\title{
TRES CONCEPTOS DE HISTORIA
}

\author{
ANTONIO CAMPILLO \\ Universidad de Murcia
}

\begin{abstract}
RESUMEN: Este artículo tiene un doble objetivo. En primer lugar, se pretende trazar un mapa de los diversos usos que ha adquirido el concepto de historia en el curso de la historia de Occidente. Estos diversos usos pueden ser agrupados en tres grandes campos semánticos (la historia como modo de saber, como modo de ser y como modo de hacer), a los que corresponden otras tantas maneras de entender la Filosofía de la Historia: como epistemología de la historia, como ontología de la historicidad y como crítica ético-política del propio presente. En segundo lugar, se trata de mostrar que estos tres conceptos de historia ( $\mathrm{y}$, consiguientemente, las tres maneras de entender la Filosofía de la Historia) se remiten mutuamente $y$, por tanto, son inseparables entre sí.
\end{abstract}

PALABRAS CLAVE: historia, filosofía, ciencia, tiempo, acción.

\section{Three concepts of history}

ABSTRACT: The aim of this article is twofold. On the one hand, I will outline the diverse usages that the concept of history has taken on throughout Western history. These different usages may be grouped together in three semantic fields (history as a way of knowing, as a way of being and as a way of doing), which correspond to three ways of understanding the Philosophy of History: as Epistemology of History, as Ontology of historicity and as ethical-political Critique of the present. On the other hand, I will show that these three concepts of history (and, accordingly, the three ways of understanding the Philosophy of History) refer mutually to each other and, thus, are inseparable from each other.

KEY WORDS: history, philosophy, science, Time, action.

Desde que Voltaire publicó en 1765, bajo pseudónimo, su Filosofía de la Historia —reeditada en 1769 como prólogo a su Ensayo sobre las costumbres y el espíritu de las naciones - ${ }^{1}$, el concepto de historia y, consiguientemente, la expresión filosofía de la historia han sido entendidos de muy diferentes maneras, tanto por los historiadores como por los filósofos. Estos diferentes usos remiten, a su vez, a la polisemia que el término historia ha ido adquiriendo

1 Voltaire, Filosofía de la Historia, ed. de Caparrós, M., Madrid, Tecnos, 2008, $2^{\mathrm{a}}$ ed.; Essai sur les moeurs et l'esprit des nations, 9 vols., ed. de Bernard, B., Renwick, J., Cronk, N. y Godden, J., en Euvres complètes de Voltaire, vols. 21 a 27, Oxford, University of Oxford y Fundation Voltaire, 2009-2016 (se han editado ya los vols. II a VIII, y en 2016 se editarán el I y el IX); Ensayo sobre las costumbres y el espíritu de las naciones, Buenos Aires, Hachette, 1959. Sobre la «filosofía de la historia» de Voltaire: MeInecke, F., El historicismo y su génesis, México, FCE, 1983, pp. 71-106; Cassirer, E., Filosofía de la ilustración, México, FCE, 1943, cap. V, «La conquista del mundo histórico», pp. 221-259; Ferrater Mora, J., Cuatro visiones de la historia universal: San Agustín, Vico, Voltaire, Hegel, Madrid, Alianza, 1982; Pujol, C., Voltaire, Madrid, Palabra, 1999; Domínguez, M., «Estudio introductorio: Voltaire y su filosofía», en Voltaire, Obras, trad. de Savater, F., de Dampierre, C. R., Martínez Drake, L. y Armiño, M., prólogo de Savater, F., Madrid, Gredos, Biblioteca Grandes Pensadores, 2010, pp. I-CXII. 
en las lenguas del Occidente euro-atlántico desde su aparición en la Grecia antigua, y especialmente desde finales del siglo XVIII ${ }^{2}$.

Esta cambiante polisemia de la palabra historia, y, con ella, de la expresión filosofía de la historia, no hace sino revelar las complejas relaciones de alianza y de litigio que han mantenido entre sí la Historia y la Filosofía, desde que ambas nacieron en la Grecia antigua como dos formas de conocimiento más o menos instituidas. Para orientarnos en esta tierra de nadie situada entre el territorio de la Historia y el de la Filosofía, en esta región fronteriza y fluctuante en donde todos los senderos se bifurcan y se entrecruzan una y otra vez, en el presente artículo voy a trazar un mapa, en el que al menos queden consignados los caminos más hollados y los lugares más disputados.

Mi propuesta cartográfica es que los diversos significados del concepto historia pueden ser agrupados en tres campos semánticos: el término historia es utilizado para nombrar un cierto tipo de saber o de conocimiento, un cierto modo de ser o de estar en el mundo y una cierta forma de hacer o de actuar con respecto a la propia época. Debido a esta diversidad de usos, la Filosofía de la Historia también ha sido entendida de muy diferentes maneras: como una epistemología de la historiografía, como una ontología de la historicidad y como una crítica ético-política del propio presente histórico.

El término griego historía, derivado del sustantivo hístor (veedor o testigo) y del verbo historein (ver, conocer, investigar algo por uno mismo, pero también narrar o atestiguar ante otros lo averiguado), nace en la Grecia antigua para nombrar un cierto tipo de saber o de conocimiento acerca de los seres y sucesos del mundo, obtenido mediante la investigación empírica y expuesto mediante la narración literaria ${ }^{3}$.

En dos pasajes de la Ilíada (XVIII, 497-501, y XXIII, 486)4, aparece el término hístor para designar al "testigo», es decir, a quien sabe algo porque lo ha visto por sí mismo y puede dar testimonio de ello. Es muy significativo que en los dos

2 Para la historia de la polisemia del término historia, y sobre todo para el giro que tiene lugar a finales del siglo XVIII, son imprescindibles los estudios de "historia conceptual» de Koselleck, R., Futuro pasado. Para una semántica de los tiempos históricos, trad. de Smilg, N., Barcelona, Paidós, 1993, e historia/Historia, ed. de Gómez Ramos, A., Madrid, Trotta, 2010. Véase también el ya clásico ensayo de ARENDT, H., «El concepto de historia: antiguo y moderno", en Entre el pasado y el futuro. Ocho ejercicios sobre la reflexión filosófica, trad. de PolJak, A., Barcelona, Península, 2003, pp. 49-100.

3 Lozano, J., El discurso histórico, Madrid, Alianza, 1987, pp. 15-25; Casertano, M., Bonaccorso, G., y Ferrara Romeo, S, Istorika. Metodi e forme della storiografia greca, Palermo, Brotto, 1987; Momigliano, A., La historiografía griega, Barcelona, Crítica, 1984; Shotwell, J. T., Historia de la historia en el mundo antiguo, Madrid, FCE, 1982; СнÂTELET, F., El nacimiento de la Historia: la formación del pensamiento historiador en Grecia, 2 vols., Madrid, Siglo XXI, 1978.

4 Homero, Ilíada, versión rítmica de García Calvo, A., Zamora, Lucina, 1995, pp. 472 y 568. 
pasajes homéricos citados se mencione - y se recurra- al testigo con ocasión de un litigio entre dos personajes. El testigo actúa en ambos casos como mero veedor, pero no como juez. Antes de que la pólis democrática instituyera los tribunales de justicia y recurriera al testimonio de los testigos, uno de los modos tradicionales de resolver los litigios era el juramento, pero los litigantes que juraban no hacían sino poner a los dioses por testigos y jueces, y pedirles castigo para el que jurase en falso: «¡Sepa [vea, atestigüe] (historoúnton) el primero Zeus, de los dioses sumo y supremo, y Tierra y Sol y las Furias que bajo la tierra tremendo castigo a todo hombre le dan que perjure en su juramento...»(Ilíada, XIX, 258 ss.) $)^{5}$. En todos estos usos del sustantivo hístor y del verbo historein, se recurre al testigo (sea humano o divino) cuando surge un conflicto o desacuerdo en torno a la verdad de lo sucedido, y se toma la visión directa de los hechos como criterio de juicio o de verdad, de modo que la verdad del testimonio aparece vinculada a la práctica de la justicia. Ahora bien, el nacimiento de la pólis democrática supone el tránsito de la justicia divina a la justicia humana, es decir, del mythos como relato del «tiempo de dioses» a la historía como relato del «tiempo de hombres» ${ }^{6}$.

Para los griegos, el «historiador» es, ante todo, el «testigo» (hístor), el que sabe algo porque lo ha visto o averiguado por sí mismo, y el valor de verdad de su conocimiento acerca de tales o cuales sucesos se funda precisamente en el hecho de que han sido observados, investigados y atestiguados por él mismo, es decir, en el hecho de que han sido conocidos por la experiencia directa de los sentidos, sean los sentidos del propio historiador o los de otros testigos cuyos testimonios han sido deliberadamente recabados y contrastados por él. Pero el historiador es también el «narrador», el que da testimonio de lo que ha visto mediante un relato de los hechos, el que posee un saber adquirido por propia experiencia y al que se concede, por tanto, la autoridad para transmitirlo o contarlo a los demás, en fin, el que manifiesta públicamente la verdad de lo que ha averiguado y se compromete personalmente con ella, poniendo su propio nombre como garantía última del valor de lo dicho, mediante una narración escrita y suscrita por su autor. De este modo, la Historia es tanto la investigación o averiguación de lo sucedido, como la narración de lo investigado o averiguado. Y, de hecho, el término historía fue empleado en la Grecia antigua con ambos significados.

El nacimiento de la Historia es paralelo al de la Filosofía ${ }^{7}$, y supone un cambio en la manera de concebir la verdad. En los inicios de la Grecia

Homero, Ilíada, op. cit., pp. 485-486.

6 Vernant, J.-P., Mito y pensamiento en la Grecia antigua, Barcelona, Ariel, 1973; VidalNaquet, P., «Tiempo de dioses y tiempo de hombres», en Formas de pensamiento y formas de sociedad en el mundo griego. El cazador negro, Barcelona, Península, 1983, pp. 61-85; Detienne, M., Los maestros de verdad en la Grecia arcaica, prefacio de VIDAL-NAQuET, P., Madrid, Taurus, 1981; Foucault, M., La verdad y las formas jurídicas, Barcelona, Gedisa, 1980, pp. 35-60.

7 Vernant, J.-P., Los orígenes del pensamiento griego, Barcelona, Paidós, 1992; Martínez Marzon, F., «En torno al nacimiento del título «Filosofía»», en De Grecia y la Filosofía, Murcia, Editum, 1990, pp. 11-39; Lledó, E., «Notas semánticas sobre el origen de la filosofía y de su historia», en Lenguaje e historia, Barcelona, Ariel, 1978, pp. 89-132. 
clásica, coincidiendo con el surgimiento de la pólis democrática, comienza a privilegiarse la vista sobre el oído. El saber que se busca es un saber ocular, visual, contemplativo: es el saber del espectador, es decir, del testigo directo que al mismo tiempo se mantiene a distancia de los hechos, como un observador imparcial, sea la imparcialidad del extranjero que viene de fuera o la del juez que se sitúa por encima de las partes. En el uso más antiguo del término philosophós, cuya invención es atribuida a Pitágoras y fechada hacia el 530 a.C., se lo compara con el espectador (theorós) que asiste a unos juegos olímpicos como mero testigo, por oposición al atleta que busca la gloria y al mercader que busca la riqueza ${ }^{8}$. En el fragmento más antiguo donde aparece la palabra philosophós, Heráclito identifica la figura del filósofo con la del historiador: «Pues bien han de ser de muy muchas cosas investigadores (historas) los hombres aspirantes a sabiduría (philosóphous ándras)»9.

Pero, entendámoslo bien: no se trata de privilegiar el «sentido de la vista» frente al "sentido del oído», sino más bien una determinada concepción de la verdad frente a otra. Solo se admite como verdad lo observado empíricamente por uno mismo (autópsia) y no ya lo escuchado de otros (ákoe), como un rumor que circula de boca en boca, como una tradición que se repite de generación en generación. Frente a la autoridad de la tradición oral y anónima, se afirma la autoridad del testigo ocular que se pone a sí mismo como garante de la verdad de lo dicho y que incluso lo escribe y suscribe con su nombre. Frente al mythos como un relato colectivo que es transmitido oralmente y que remite a un pasado inmemorial, la historía aparece como un relato del testigo directo de los hechos, que pone su testimonio por escrito y que lo firma con su nombre de autor.

Heródoto de Halicarnaso es el autor de la primera Historia, obra inaugural de la historiografía occidental ${ }^{10}$. En ella narra, entre otros muchos sucesos, las «guerras médicas» (490-479 a.C.), es decir, la decisiva contienda entre el imperio persa y la confederación de las ciudades griegas, que instituyó la división entre Europa y Asia $^{11}$. No obstante, en el inicio mismo de su relato, anuncia que va a narrar «las notables y singulares empresas realizadas, respectivamente, por griegos y bárbaros», proclamando así su pretensión de imparcialidad, es decir, su propósito de ser justo con unos y otros ${ }^{12}$. Pues bien, Heródoto vincula esta voluntad de hacer justicia a griegos y bárbaros, con el privilegio concedido a la observación directa de sus acciones por parte del propio narrador, en cuanto testigo u observador imparcial. Aunque ello no le impide narrar también, tras viajar por varios países mediterráneos, lo que ha escuchado de boca de otros.

8 Cicerón, Disputaciones Tusculanas, ed. de Medina, A., Madrid, Gredos, 2005, Lib. V, caps. 3/7 a 4/11, pp. 390 ss.

9 Heráclito, Razón común, edición crítica, ordenación, traducción y comentario de los restos del libro de Heráclito, por García CAlvo, A., Madrid, Lucina, 1985, fr. 22, pp. 78-80.

10 Heródoto, Historia, 3 vols., ed. de Schrader, C., Madrid, Gredos, 1977-1984-1986.

11 CAcciari, M., Geo-filosofía de Europa, Madrid, Aldebarán, 2001, y Europa o la filosofía, Madrid, Antonio Machado, 2007.

12 Heródoto, Historia, Proemio, op. cit., vol. I, p. 85. 
Por eso, cuando concluye la descripción geográfica y etnográfica del Egipto que él mismo ha recorrido, y se dispone a narrar su pasado histórico, nos advierte:

Todo cuanto he dicho hasta este punto es producto de mis observaciones, consideraciones y averiguaciones personales; pero, a partir de ahora, voy a atenerme a testimonios egipcios tal como los he oído, si bien a ellos añadiré también algunas observaciones mías. ${ }^{13}$

Una generación después, Tucídides adopta un método mucho más exigente. Su relato se circunscribe a un espacio y un tiempo más reducidos y mejor medidos que aquellos por los que se mueve el viajero y crédulo Heródoto. La publicación en el año 425 a.C., por Hellánicos de Mitilene, de una Cronología de las sacerdotisas de Argos, establecida con referencia a los juegos de Esparta, permite a Tucídides contar y fechar su Historia de la Guerra del Peloponeso siguiendo el curso cronológico del calendario, hasta el año 408. Además, en su relato se atiene muy estrictamente al principio de la observación directa: narra solo la historia de una contienda de la que había sido actor y espectador; en efecto, era estratega ateniense cuando fue vencido en Tracia (424 a.C.) y condenado al destierro hasta el retorno de la paz. Por eso, dice con orgullo:

En cuanto al relato de los acontecimientos de la guerra, para escribirlo no me he creído obligado a fiarme ni de los datos del primer llegado ni de mis conjeturas personales; hablo únicamente como testigo ocular o después de haber hecho una crítica lo más cuidadosa y completa posible de mis informaciones. La investigación ha sido ardua, ya que los testigos de cada hecho presentan versiones que varían según su simpatía respecto de unos y otros, y según su memoria. ${ }^{14}$

Cuando el historiador no puede apelar a la propia observación, sino a lo observado por otros, decide someter el relato de los testigos a una cuidadosa «crítica» (akribía), contrastando entre sí los diferentes testimonios, ya que estos varían en función de la memoria y de las inclinaciones partidistas de unos y otros. Por eso, Tucídides no actúa solo como un simple testigo, sino más bien como el juez de un tribunal, cuya función consiste precisamente en juzgar (krinein), es decir, discriminar entre lo verdadero y lo falso, a partir de los diversos testimonios de los testigos; aunque, en este caso, no se juzga un litigo entre individuos o familias de una misma pólis, sino más bien una guerra entre diferentes póleis o comunidades políticas. Como el juez que emprende una investigación judicial, el historiador recaba la información de los testigos, contrasta sus diferentes testimonios —entre sí y con el suyo propio-, y de este modo, por medio de una indagación metódica e imparcial, acaba reconstruyendo la verdad de lo sucedido. En resumen, Tucídides considera que la observación directa de los hechos y la contrastación crítica de unos testimonios con otros, son el más seguro criterio de verdad.

13 Heródoto, Historia, II, 99, op. cit., vol. I, p. 385.

14 Tucídides, Historia de la Guerra del Peloponeso, I, 22, ed. de Rodríguez Adrados, F., Barcelona, Crítica, 2013. 
Ahora bien, desde el momento en que el valor de verdad de la investigación histórica se hace depender de la observación directa de los hechos y del testimonio de los testigos presenciales, es obvio que dicha investigación debe limitarse a aquellos sucesos de los que hay supervivientes. En otras palabras, solo es posible lo que Hegel llamó la «historia inmediata», es decir, la crónica del presente más o menos próximo, en la que el historiador es contemporáneo de los hechos que investiga y que narra. Y, en efecto, esta es una característica común de toda la historiografía griega y romana: ambas son «historia inmediata», como constatan Momigliano y Châtelet ${ }^{15}$. Y esta característica se mantuvo también en las obras de los cronistas medievales e incluso en las historias de las Indias orientales y occidentales, redactadas por los conquistadores y misioneros europeos entre los siglos xVI y xvIII. Desde la Antigüedad hasta la Ilustración, los historiadores tenían que centrar la mayor parte de su relato en el pasado cercano, y solo podían remontarse al pasado lejano recurriendo a mitos y leyendas populares, o bien a especulaciones filosóficas y teológicas más o menos compartidas, como la concepción greco-latina de los ciclos cósmicos, el dogma cristiano de la providencia divina que rige el curso del mundo o la creencia ilustrada en el progreso universal de la humanidad.

Pero, en la Grecia antigua, el término historía no nombra solo la investigación y narración de los asuntos humanos, sino también la investigación y narración de todos los fenómenos que componen la Physis, es decir, el conjunto de la Naturaleza. Por eso, los discípulos de Aristóteles llamaron Historia de los animales a la compilación de sus investigaciones zoológicas ${ }^{16}$. A fin de cuentas, se consideraba que los asuntos humanos estaban sujetos a las mismas leyes y ciclos recurrentes que los fenómenos naturales. Este es otro de los parentescos que unen desde su origen a la Historia y la Filosofía. En un célebre pasaje del Fedón (96 a), en el que Sócrates narra a Cebes el recorrido intelectual que le llevó del estudio de los fisiologoi al descubrimiento de Anaxágoras y de su tesis sobre la inteligencia (noûs) como principio rector del mundo, Platón llega a definir la filosofía de los primeros sabios griegos como una physeos historía («historia de la naturaleza»). Esta «historia de la naturaleza» sería, para Platón, una especie de filosofía incipiente o primitiva, un primer paso hacia la verdadera filosofía ${ }^{17}$.

De modo que la historía, como un nuevo modo de saberbasado en el testimonio, se ocupaba de los seres y sucesos humanos, pero también de los seres y sucesos no humanos (fuesen celestes o terrestres, supralunares o sublunares), en la medida en que unos y otros formaban parte del mundo fenoménico, es decir, en la medida en que se presentaban ante la percepción humana en el mundo de las apariencias sensibles.

15 Momigliano, A., La historiografía griega, o.c., pp. 47-48; Сhâtelet, F., El nacimiento de la Historia, op. cit., vol. I., pp. 22-23.

16 Aristóteles, Investigaciones sobre los animales, ed. de Pallí Bonet, J., intr. de García Gual, C., rev. de Martín Vázouez, L., Madrid, Gredos, 1992.

17 Platón, Diálogos III. Fedón, Banquete, Fedro, ed. de García Gual, C., Martínez HernándeZ, M. y Lledó Í̃̃̃IGo, E., Madrid, Gredos, 1986, pp. 101 ss. 
En su origen, pues, la Historia nace como un cierto tipo de saber o de discurso acerca de los seres y sucesos del mundo fenoménico, fundado en la investigación empírica y expuesto mediante la narración literaria. El término griego historía designaba el acto de atestiguación en su doble e inseparable vertiente: investigación empírica o atestiguación por sí mismo de tal o cual presencia fenoménica, y narración literaria o atestiguación ante los otros de lo que uno mismo ha visto o averiguado.

Por tanto, el término griego historía era sinónimo de lo que nosotros llamamos hoy ciencia, pues nombraba todo saber empírico basado en la atestiguación sensorial. Ese saber podía ocuparse exclusivamente de los seres y sucesos humanos, y en tal caso era «historia moral»: el historiador griego Polibio la llamó pragmatiké historía o «historia de las acciones humanas» realizadas por los pueblos y sus dirigentes políticos ${ }^{18}$; en 1769 , Voltaire la llamó «historia de las costumbres»; y, a comienzos del siglo xix, John Stuart Mill la incluyó entre las «ciencias morales» ${ }^{19}$. Pero el saber histórico también podía ocuparse de los seres y sucesos no humanos, y en tal caso era «historia natural», una expresión que, como ya he dicho, utiliza Platón en el Fedón, que retoma Plinio el Viejo en su Naturalis Historia y que se mantendrá vigente hasta finales del siglo XVIII, en naturalistas como Buffon o Linneo. Porque la distinción ontológica entre ambos tipos de seres y de sucesos (y, por tanto, la distinción epistemológica entre ambos tipos de saberes) no era entendida en la Grecia antigua de forma dicotómica, al menos no como lo será en la época moderna, especialmente a partir de Descartes.

Por otro lado, el término historía era sinónimo de lo que nosotros llamamos hoy relato, es decir, toda composición discursiva en forma de narración retrospectiva, en la que los sucesos se encadenan siguiendo un cierto orden o hilo argumental. Pero el relato histórico se presentaba en Grecia como un relato verídico y escrito, garantizado por el testimonio y el nombre de su autor, y, por tanto, pretendía diferenciarse netamente de los relatos orales tradicionales (mitos, epopeyas y cuentos populares), y también de las composiciones literarias deliberadamente ficticias (tragedias, comedias y novelas).

\section{II}

Los filósofos griegos y latinos atribuyeron a este nuevo saber llamado Historia una gran utilidad práctica para orientarse en el mundo, pero no le reconocieron el estatuto de ciencia en el sentido de saber supremo o episteme, puesto que no era capaz de suministrar principios universales y eternos acerca de los seres y sucesos del mundo. De hecho, la Historia no era objeto

18 Polibio, Historias, IX 1, 2, ed. de Balasch, M., rev. de Guzmán, J. M., intr. de Díaz TeJera, A., 3 vols., Madrid, Gredos, 1983-1990-1997.

19 Stuart Mill, J., La lógica de las ciencias morales, trad. de Álvarez, J. F. y KiczKowski, A., Madrid, CSIC, 2010. 
de transmisión académica, no formaba parte de las siete «artes liberales» que se enseñaban en las escuelas antiguas y en las universidades medievales: el trivium o las letras y el quadrivium o las ciencias. Era, más bien, un saber moral o prudencial, una colección de «ejemplos» memorables que podía ser muy útil para los gobernantes y hombres de acción, pues se daba por supuesta la invariabilidad de la naturaleza humana. Así lo expresa el adagio latino: Historia magistra vitae.

A partir de Platón y Aristóteles, la episteme como «ciencia suprema» comienza a ser identificada con la Filosofía, y esta a su vez con la Teología, es decir, con un saber divino acerca del origen primero y el fin último de todos los seres ${ }^{20}$. Aquí es donde se bifurcan la Historia y la Filosofía. Mientras que la primera se ocupa de los seres que nacen y perecen contingentemente en el mundo fenoménico, la segunda se ocupa de los seres eternos y de los principios igualmente eternos, universales y necesarios que gobiernan el conjunto del kósmos. La Historia es considerada por Platón y Aristóteles como una mera doxa, como un saber relativo y cambiante sobre sucesos igualmente cambiantes y relativos. Por eso, no cabe otra «filosofía de la historia» que la de su denegación, ni otra "historia de la filosofía» que la de las doxografías tan habituales en la Antigüedad greco-latina, como las Vidas de filósofos ilustres, de Diógenes Laercio. Entre la Historia y la Filosofía no se acepta otra relación que la de su mutua exclusión o su estricta jerarquización, y el filósofo reclama para sí el lugar más preeminente.

En su Poética, Aristóteles llega a considerar que la narración ficticia del poeta épico o trágico, en la medida en que representa arquetipos humanos universales y se rige por el principio narrativo de la verosimilitud, que exige una cierta necesidad lógica en el desarrollo de la acción, es «más filosófica y elevada» que la narración verídica del historiador, en la medida en que esta se limita a hablar de individuos y acciones que se han dado realmente en el mundo, sí, pero que lo han hecho de modo singular y contingente, sin poseer un carácter universal ni responder a necesidad alguna:

Y también resulta claro por lo expuesto que no corresponde al poeta decir lo que ha sucedido, sino lo que podría suceder, esto es, lo posible según la verosimilitud o la necesidad. En efecto, el historiador y el poeta no se diferencian por decir las cosas en verso o en prosa (pues sería posible versificar las obras de Heródoto, y no serían menos historia en verso que en prosa); la diferencia está en que uno dice lo que ha sucedido, y el otro, lo que podría suceder. Por eso también la poesía es más filosófica y elevada que la historia; pues la poesía dice más bien lo general, y la historia, lo particular.

20 Aristóteles, Ética a Nicómaco, ed. bilingüe de Araujo, M. y Marías, J., intr. y notas de Marías, J., Madrid, Centro de Estudios Políticos y Constitucionales, 2002 (1 $1^{\text {a }}$ ed. 1949), Lib. VI, 1138b 18 - 1145a 11, pp. 88-102; Metafísica, ed. trilingüe de García Yebra, V., Madrid, Gredos, 1982, $2^{\text {a }}$ ed. revis., Lib. I, 980a 21 - 983b 6, pp. 2-20, y Lib. IV, 1003a 21 - 1006a 34, pp. 150-169; Aubenoue, P., El problema del ser en Aristóteles, trad. de PeÑa, V., Madrid, Escolar y Mayo, 2008. 
En general a qué tipo de hombres les ocurre decir o hacer tales o cuales cosas verosímil o necesariamente, que es a lo que tiende la poesía, aunque luego ponga nombres a los personajes; y particular, qué hizo o qué le sucedió a Alcibíades. ${ }^{21}$

A partir de los siglos XVI y XVII, el nacimiento de las modernas ciencias naturales, basadas en la observación empírica de los fenómenos, pero también en su cuantificación matemática, su reproducción experimental y su manipulación técnica, hará que el término ciencia acabe diferenciándose de los términos filosofía y teología (e incluso contraponiéndose polémicamente a ellos, sobre todo a partir del positivismo del siglo XIX), mientras que el término historia acabará reservándose exclusivamente para el conocimiento y relato de los asuntos humanos. Paralelamente, este saber histórico ya no se limitará a la observación directa de las acciones y costumbres humanas (sean las costumbres propias de la moderna sociedad occidental, cuyo estudio dará origen a la Sociología, o las costumbres de los pueblos no europeos colonizados por Occidente, cuyo estudio dará origen a la Antropología social y cultural), sino que se extenderá también al estudio filológico y arqueológico de los documentos y monumentos legados por los antepasados, de modo que la Historia dejará de ser la crónica del presente inmediato y pasará a convertirse en la reconstrucción del pasado lejano.

En efecto, a partir del siglo XIX, la Historia como un cierto tipo de saber deja de ser la crónica periodística y etnográfica del presente inmediato y se convierte en el estudio erudito de todas las épocas del pasado. Y para ello recurre a dos «testigos» no vivientes, los documentos y los monumentos, y a dos saberes auxiliares que interrogan a esos testigos: la Filología y la Arqueología. El historiador deja de ser un viajero y se convierte en un investigador de archivo. Así es como comienzan a componerse las grandes Historias de la cultura occidental, desde la Antigüedad hasta la Modernidad, e incluso las Historias de las otras grandes civilizaciones con tradición escrita.

Además, la Historia renuncia a ser un saber meramente moral o prudencial (la «maestra de la vida»), y pretende constituirse como un saber científico en el sentido moderno del término, como una ciencia «de hechos» y no "de valores», análoga a la Física, la Química y la Biología. La Historia ya no se contenta con ser una mera colección inconexa de crónicas de acciones y actores ejemplares, sino que pretende componer, pieza a pieza, el gran relato científico de la Historia Universal de la Humanidad, entendida como un proceso causal único, sujeto a leyes inexorables. A esta transformación se refiere críticamente Hannah Arendt en el ensayo ya citado.

En general, todos los saberes histórico-sociales (Historia, Sociología, Economía, Antropología social y cultural, Psicología, etc.) trataron de conquistar el estatuto de ciencias y afirmaron su autonomía frente a la

21 Aristóteles, Poética, ed. trilingüe de García Yebra, A., Madrid, Gredos, 1974, Lib. 9, pp. 157-158. 
Filosofía y la Teología, mediante un doble movimiento de identificación y diferenciación con respecto a las ciencias naturales. En la medida en que pretendían constituirse como ciencias en el sentido moderno del término, se vieron enfrentadas a un gran dilema: o adoptar el método propio de la Física matemática newtoniana (la «explicación» causal por leyes deterministas), como proponían los positivistas Comte y Stuart Mill, o elaborar sus propios métodos de conocimiento (comenzando por el método de la «comprensión» hermenéutica), como proponían Dilthey y Weber, entre otros. Los debates en torno al estatuto específico de las ciencias histórico-sociales dieron origen a un tipo de reflexión epistemológica que constituye hoy uno de los tres grandes dominios de la Filosofía de la Historia ${ }^{22}$.

Aunque Miguel de Cervantes, a comienzos del siglo xvII, llamaba «historias» a sus novelas y se llamaba a sí mismo "historiador», y aunque ciencias como la zoología y la botánica fueron consideradas hasta fines del siglo XVIII como partes de la «historia natural», en los dos últimos siglos la Historia ha pasado a ser considerada exclusivamente como un relato verídico o «científico» acerca de los seres y sucesos humanos. Sin embargo, la distinción y la relación entre ciencias histórico-sociales y ciencias naturales, así como la distinción y la relación entre narración verídica y narración de ficción, ha dado lugar a las más diversas opiniones y a los más enconados debates, y todas estas opiniones y debates constituyen hoy, como ya he dicho, uno de los tres grandes dominios de la Filosofía de la Historia: el dominio epistemológico.

A pesar de la enorme distancia temporal y cultural que separa a Heródoto de los historiadores actuales, podemos concluir que la Historia, entendida como un cierto tipo de saber, ha conservado en todo momento su doble condición de investigación empírica y narración literaria, y esta híbrida condición de ciencia narrativa o narración científica le ha permitido desempeñar el ambiguo papel de frontera y de puente entre las exigencias empíricas de la ciencia y las exigencias retóricas del relato.

En resumen, este es el primer significado del término historia: un cierto tipo de saber, a un tiempo científico y narrativo, sobre los seres y sucesos del mundo fenoménico, y en particular sobre los seres y sucesos humanos. En la medida en que nos atengamos a este significado, la Filosofía de la Historia puede ser entendida como una parte de la Filosofía de la Ciencia, es decir, como una reflexión epistemológica sobre el estatuto científico o epistémico del saber histórico, sobre sus métodos y objetos de conocimiento, sobre sus afinidades y diferencias con otro tipo de saberes, etc. En una palabra, la Filosofía de la Historia sería una mera rama de la Epistemología.

22 Ricoeur, P., Tiempo y narración, o.c.; Roldán, C., Entre Casandra y Clío. Una historia de la filosofía de la historia, prólogo de Muguerza, J., Madrid, Akal, 1997; Bourdé, G., y MARTin, H., Las escuelas históricas, Madrid, Akal, 1992; Wallerstein, I., "Análisis de los sistemas mundiales», en Giddens, A., y TuRner, J. H. (eds.), La teoría social hoy, Madrid, Alianza, 1990, pp. 398-417; CAmPILlo, A., "Historia y Ciencias Sociales: de la Ilustración a la Globalización», en Larrea, J. J., y Pastor, E., (eds.), La Historia desde fuera, Bilbao, EHU/UPV, 2009, pp. 13-26. 
Pero el término historia, nacido para nombrar la ciencia narrativa de los seres y sucesos que aparecen en el mundo fenoménico, se utilizó también para nombrar a esos mismos seres y sucesos de los que el historiador se ocupaba. Era histórico no solo el relato subjetivo de los hechos acontecidos (la historia rerum gestarum), sino también el acontecer objetivo de tales hechos (las res gestae), eso que ya Agustín de Hipona llamó la «historia misma» (historia ipsa). Para Agustín, una cosa es el relato de las acciones humanas, tal y como es compuesto por el historiador, y otra cosa es la "historia misma», que no es una institución humana sino divina (La doctrina cristiana, 2, 28, 44) ${ }^{23}$.

Se produjo así una inversión cargada de consecuencias: los seres y sucesos del mundo no llegaban a ser históricos porque se diese un expreso y subjetivo testimonio de ellos, sino que podía darse testimonio de ellos en la medida en que eran objetivamente históricos, es decir, en la medida en que lo eran por sí mismos, independientemente de todo testimonio manifestado sobre ellos. Ahora bien, si lo "histórico» era, en su origen, lo efectivamente atestiguado (mediante la investigación y la narración), es evidente que para hablar de seres y sucesos «históricos» en sí mismos, independientemente de toda atestiguación efectiva, había que atribuir al término historia una nueva significación.

En efecto, el término historia fue utilizado para nombrar no solo un modo de saber acerca del mundo, sino también un modo de ser del propio mundo, o de ciertos entes del mundo. Tanto en la filosofía greco-latina como en la judeo-cristiana, tanto en el poema de Parménides como en el relato bíblico del Génesis, el mundo mismo se divide en dos grandes dimensiones ontológicas: la eterna y la temporal, la celeste y la terrestre, la del Ser que es siempre y la de los seres que nacen y perecen en el curso del tiempo, y entre los cuales nos encontramos nosotros los humanos, llamados en la Ilíada los «mortales» y en la Biblia las «criaturas». Estos seres, en la medida en que están (o estamos) sometidos al orden del tiempo, son (o somos) constitutivamente históricos. En el pensamiento greco-latino, ese orden del tiempo es eterno y cíclico; en el pensamiento judeo-cristiano, es un orden creado y providencial, con un principio y un fin absolutos, y con una promesa de redención o salvación más allá de la muerte; pero, en uno y otro pensamiento, los humanos están (o estamos) sujetos al orden inexorable del tiempo, y solo un espíritu divino puede permitirles (o permitirnos) la posibilidad de trascenderlo.

En el pensamiento moderno, especialmente en la tradición idealista que va de Descartes a Kant, las dos dimensiones del mundo son la res extensa y la res cogitans, la naturaleza y el espíritu, el reino de la necesidad y el reino de la libertad. Es entonces cuando los seres humanos, en cuanto seres pensantes y espíritus libres, se atribuyen a sí mismos, de forma exclusiva, la condición

23 SAn Agustín, La doctrina cristiana, en Obras completas, vol. XV: Escritos bíblicos I: La doctrina cristiana. Comentario al Génesis en réplica a los maniqueos. Comentario literal al Génesis, Madrid, BAC, 1957. 
histórica; pero esa historicidad no consiste ya en la sumisión al orden cíclico o providencial del tiempo, sino más bien en la capacidad utópica para imponer a ese orden una dirección determinada, un movimiento teleológico y, por tanto, una promesa de redención terrenal o de trascendencia intramundana.

En el tránsito del siglo XVIII al XIX, el desarrollo mismo de los saberes histórico-sociales hará que el término historia comience a ser utilizado de forma cada vez más frecuente y sistemática no solo para nombrar un cierto tipo de saber, sino también un cierto tipo de ser, precisamente el ser humano. En autores como Herder y Hegel ${ }^{24}$, el ser humano deja de ser pensado como un mero ser natural, similar a cualquier otra criatura viviente, y pasa a ser pensado como un ser histórico, esto es, no como una especie ya formada desde el origen, de una vez por todas y para siempre, sino como una especie que puede adoptar las formas más diversas ${ }^{25}$. Hasta entonces, incluso entre los filósofos ilustrados, se consideraba que el ser humano es siempre el mismo, que su «naturaleza» no difiere de un lugar a otro y de uno a otro tiempo, y que su existencia está sujeta a las mismas leyes que las del resto de seres naturales. Por eso, precisamente, tenía validez el adagio latino Historia magistra vitae: la narración de los hechos del pasado podía servir de ejemplo y de guía para el porvenir. Desde finales del siglo XVIII, tras las primeras revoluciones políticas, el surgimiento del capitalismo industrial y la crítica romántica al racionalismo ilustrado, este adagio comienza a ser cuestionado. Comienza a establecerse una dicotomía entre el reino de la naturaleza, sometido a leyes universales y eternas, y el reino del espíritu, caracterizado por la diversidad de los pueblos y por el dinamismo interno de su singular existencia histórica.

El término historia ya no nombra solo un cierto modo de saber sino también un cierto modo de ser, el modo de ser de los humanos, que, a diferencia del resto de los seres naturales, se constituyen a sí mismos históricamente, es decir, en el seno de una determinada comunidad cultural y en el curso sucesivo de las generaciones.

En el último tercio del siglo xix y el primero del xx, filósofos como Nietzsche y Heidegger cuestionan el dualismo greco-cristiano de naturaleza y espíritu, pero también la moderna teleología histórica que conduce de la una al otro ${ }^{26}$.

24 Herder, J. G., Ideas para una Filosofía de la Historia de la Humanidad, Buenos Aires, Losada, 1959, y Otra Filosofía de la Historia para la Educación de la Humanidad, en Obra selecta, ed. de Ribas, P., Madrid, Alfaguara, 1982, pp. 273-367; Hegel, G. W. F., Lecciones sobre la filosofía de la historia universal, Madrid, Madrid, 1980.

25 Esta concepción «camaleónica» del ser humano se encuentra ya en Giovanni Pico della Mirandola (De la dignidad del hombre, ed. de MARTínez Gómez, L., Madrid, Editora Nacional, 1984), pero formulada desde una perspectiva teológica y no propiamente desde una perspectiva histórico-cultural.

26 Nietzsche, F., Consideraciones intempestivas II. De la utilidad e inconvenientes de la historia para la vida, en Obras completas I. Escritos de juventud, ed. de SÁnchez Meca, D., Llinares, J. B. y de Santiago, L. E., Madrid, Tecnos, 2011; Heidegger, M., Ser y tiempo, ed. de Rivera, J. E., Madrid, Trotta, 2003. Sobre la concepción de la historia en Nietzsche: Vermal, J. L., La crítica de la metafísica en Nietzsche, Barcelona, Anthropos, 1987; Foucault, F., Nietzsche, la Genealogía, la Historia, Valencia, Pre-textos, 1992. Sobre la concepción de la 
Paralelamente, este mismo cuestionamiento será llevado a cabo por los nuevos desarrollos de las ciencias naturales, desde el evolucionismo de Darwin hasta el indeterminismo de Heisenberg ${ }^{27}$. Entonces, volverá a replantearse el problema de la historicidad humana y de su relación con el tiempo del mundo. Pero este replanteamiento no hará sino radicalizar el reconocimiento de la historicidad constitutiva de nuestra existencia. Tanto en Nietzsche como en Heidegger, la reflexión epistemológica sobre la historiografía es remitida a una reflexión ontológica sobre la historicidad. Para que pueda darse la Historia como ciencia empírica, ha de darse previamente la historicidad como existencia trascendental. Esta existencia histórica (sea la «vida» de Nietzsche o el Dasein de Heidegger) no solo es anterior a la ciencia empírica e independiente de ella, sino que es la condición de posibilidad de su nacimiento y el fundamento último de su validez.

Así es como surge un nuevo dominio de la Filosofía de la Historia: esta es entendida no ya como epistemología sino como ontología, no ya como una reflexión sobre el estatuto científico del saber historiográfico, sino como una reflexión sobre el horizonte existencial del ser humano en cuanto ser constitutivamente histórico.

Este mismo giro de la epistemología a la ontología puede observarse en Ortega y Gasset, que en 1928 se inscribe a sí mismo en la tradición que va de Hegel a Heidegger, y que llama historiología a esta reflexión filosófica sobre la «realidad histórica»:

La historiología no es, por tanto, una reflexión metodológica sobre la historia rerum gestarum o historiografía, sino un análisis inmediato de la res gestae, de la realidad histórica. ¿Cuál es la textura ontológica de esta? ¿De qué ingredientes radicales se compone? ¿Cuáles son sus dimensiones primarias? ${ }^{28}$

\section{IV}

El tránsito del siglo XVIII al xIX es el momento en que aparece también un tercer sentido del término historia, que se manifiesta en la expresión «hacer (la) historia». Este tercer sentido ya no se refiere a un modo de saber sobre los seres y sucesos humanos (la ciencia histórica, entendida como una ciencia social entre otras), ni alude tampoco a un modo de ser de esos mismos seres y sucesos (la existencia histórica, entendida como una condición trascendental y

historia en Heidegger: Steiner, G., Heidegger, México, FCE, 1983; Peñalver, P., Del espíritu al tiempo. Lecturas de "El ser y el tiempo» de Heidegger, Barcelona, Anthropos, 1989; Vatтimo, G., Introducción a Heidegger, Barcelona, Gedisa, 1986; Ricoeur, P., Tiempo y narración, 3 vols., México, Siglo XXI, 1995-96.

27 Prigogine, I., y Stengers, I., La nueva alianza. Metamorfosis de la ciencia, Madrid, Alianza, 1983; Bocchi, G. y Ceruti, M., El sentido de la historia. La historia como encadenamiento de historias, Madrid, Debate, 1994.

28 Ortega y Gasset, J., "La Filosofía de la Historia de Hegel y la historiología», en Hegel, G. W. F., op. cit., pp. 15-32. La cita se encuentra en la p. 30. Véase también: Ortega y GASSET, J., Historia como sistema y otros ensayos de Filosofía, Madrid, Alianza, 2008. 
universal, inherente a todos los seres humanos y constitutiva de la humanidad como tal), sino que se refiere a un modo de hacer, precisamente el «hacer (la) historia», es decir, el entender la historia como una "obra» o una "acción» libre y consciente de los seres humanos. Ahora bien, este modo de hacer no sería ya común a todos los seres humanos, sino que sería más bien el rasgo distintivo y exclusivo de una sola sociedad humana: la moderna sociedad occidental.

En efecto, la expresión "hacer (la) historia» pone en juego un tercer concepto de historia, con el que se nombra una cierta manera de configurar la acción ético-política. Me refiero a la configuración utópica o proyectiva, es decir, a la voluntad colectiva de una determinada comunidad que, de forma deliberada y programada, decide modelar su propio devenir histórico y emanciparse así de los designios divinos, de los azares del destino e incluso de las leyes de la Naturaleza. Es sabido que el concepto kantiano de Ilustración alude a esta voluntad colectiva que pretende "salir de la minoría de edad» y modelar el porvenir de la humanidad de forma autónoma y racional, mediante una federación de repúblicas libres que haga posible la «paz perpetua». Es también sabido que Kant distingue entre la "historia empírica», de la que se ocupan los historiadores, y la «historia filosófica» (es decir, la Filosofía de la Historia), cuya tarea consiste en interpretar la historia de la humanidad (la ya pasada, la que acontece actualmente y la que aún está por venir) «en clave cosmopolita», es decir, a partir de un cierto ideal ético-político que debe ser realizado por nosotros mismos. Y es igualmente sabido que este modo de entender la acción ético-política no es común a todas las sociedades humanas, sino que es más bien el modo en que la moderna sociedad occidental se ha conceptualizado a sí misma, al menos desde la Ilustración en adelante ${ }^{29}$.

Este tercer concepto de historia no alude, pues, a un modo de saber basado en la investigación empírica y la narración literaria, ni a un modo de ser que sería común a todos los seres humanos, sino a un modo de hacer con el que podríamos caracterizar el destino singular de la moderna sociedad occidental, en la medida en que, paralelamente a su gran expansión mundial, el Occidente euro-atlántico se habría caracterizado por auto-comprender su ser histórico mediante el saber historiográfico y por auto-proyectarlo hacia el futuro y hacia el resto del mundo mediante la planificación utópica.

Mediante este tercer concepto de historia, la moderna sociedad occidental se entiende a sí misma como la única sociedad histórica, la única en la que el ser histórico adquiere conciencia de sí mediante el saber historiográfico y mediante el hacer la historia, más aún, la única que se auto-constituye y auto-afirma por encima de las demás sociedades, como enjuiciadora y hacedora del destino universal de la humanidad.

29 Kant, I., En defensa de la Ilustración, tr. de Alcoriza, J. y Lastra, A., intr. de Villacañas, J. L., Barcelona, Alba, 1999; Campillo, A., «La invención de la Historia Universal» y «Hacer lo (im)posible», en El concepto de lo político en la sociedad global, Barcelona, Herder, 2008, pp. 57-88 y 121-145, y «Sobre las formas y los límites de la emancipación», en Isegoría. Revista de Filosofía Moral y Política, 43 (2010), pp. 659-669. 
Pues bien, la interrogación por esta singularidad histórica del Occidente euro-atlántico dará lugar a un tercer dominio de la Filosofía de la Historia. La reflexión sobre el destino de Occidente y sobre el papel que ha jugado en la historia universal de la humanidad, no será entendida ya como una epistemología de la historiografía, ni como una ontología de la historicidad, sino más bien como una "crítica del presente», es decir, como un juicio inseparablemente histórico, ético y político sobre la propia actualidad, sobre el ascenso, la hegemonía y la crisis de la propia sociedad occidental. Como señaló Foucault en sus últimos años de vida, puede decirse que este tercer dominio de la Filosofía de la Historia se inicia cuando Kant se interroga por su propia actualidad y se pregunta "¿Qué es la Ilustración?» y «¿Qué es la Revolución?»30. Como ya he dicho, Kant da a esta interrogación el nombre de «historia filosófica», para diferenciarla de la «historia empírica». Foucault la llama «ontología del presente», o bien «ontología de nosotros mismos». Desde hace dos siglos, este tipo de interrogación por la propia época y por el destino de Occidente ha sido una constante de la filosofía y de las ciencias sociales contemporáneas: Hegel, Marx, Nietzsche, Weber, Arendt, la Escuela de Frankfurt y el propio Foucault no han cesado de formularla.

Tras delimitar los tres sentidos del término historia (como saber o ciencia empírica, como ser o existencia trascendental, como hacer o destino de Occidente) y, consiguientemente, los tres dominios de la Filosofía de la Historia (la epistemología de la historiografía, la ontología de la historicidad y la crítica ético-política del presente), voy a cuestionar las concepciones unidimensionales de la Filosofía de la Historia, que han pretendido zanjar en uno u otro sentido el litigio entre la Filosofía y la Historia.

En efecto, suele decirse que el término historia nombra simultáneamente dos significados diferentes: por un lado, un cierto tipo de saber o de ciencia que se ocupa de los seres humanos, las acciones que han realizado y los sucesos que les han acaecido (historia rerum gestarum); por otro lado, la realidad misma de esos seres humanos, de sus acciones y sucesos, tal y como se han sucedido unos a otros en el curso del tiempo (res gestae). Así lo afirmaba ya Hegel en sus Lecciones sobre la filosofía de la historia universal, al referirse a la doble cara, «subjetiva» y «objetiva», del término alemán Geschichte ${ }^{31}$. Y así lo han venido repitiendo desde entonces otros muchos autores.

30 Foucault, M., Sobre la Ilustración, ed. de de la Higuera, J., tr. de Bello, E., Campillo, A. y de la Higuera, J., Madrid, Tecnos, 2003.

31 Hegel, G. W. F., Lecciones sobre la filosofía de la historia universal, o.c., Introducción general, cap. III, parágrafo 3, «El comienzo de la historia», pp. 133-139. Aunque la lengua alemana cuenta con dos términos diferentes para referirse a la historia como realidad objetiva y a la historia como narración subjetiva (Geschichte e Historie), lo cierto es que ambos términos (como señala Koselleck en Futuro pasado, o.c., p. 127) son usados indistintamente para nombrar uno u otro significado. También la lengua inglesa cuenta con dos términos (History y Story), una diferencia que no se da en las lenguas románicas. 
Pero Hegel se refiere a este doble significado en términos dialécticos, para poner de manifiesto que la Filosofía de la Historia no puede ocuparse de la historia como narración subjetiva sin ocuparse simultáneamente de la historia como realidad objetiva, y viceversa. Porque, según él, «la narración histórica aparece simultáneamente con los hechos y acontecimientos propiamente históricos ${ }^{32}$; y, a la inversa, los hechos solo se convierten en hechos objetivamente históricos cuando son subjetivamente categorizados y narrados, es decir, cuando surge la conciencia histórica de los mismos.

Para Hegel, este surgimiento simultáneo de la «historia objetiva» y la «historia subjetiva» tiene lugar con la aparición de la ley escrita, es decir, con la aparición del Estado, que se presenta a un tiempo como el hacedor y el narrador de su propia historia:

Solo en el Estado existen, con la conciencia de las leyes, hechos claros y, con estos, una conciencia clara de los hechos, que da al hombre la capacidad y la necesidad de conservarlos. ${ }^{33}$

La Historia Universal, en el sentido a un tiempo objetivo y subjetivo de la palabra historia, comienza con el Estado. Por tanto, el tiempo de las sociedades sin Estado es también el tiempo de las sociedades sin Historia (en el doble sentido de la palabra), es decir, el tiempo de la Prehistoria:

Los espacios de tiempo que han transcurrido para los pueblos, antes de la historia escrita, ya nos los figuremos de siglos o de milenios, y aunque hayan estado repletos de revoluciones, de migraciones, de las más violentas transformaciones, carecen de historia objetiva, porque no tienen historia subjetiva, narración histórica. ${ }^{34}$

Aquí, Hegel está afirmando que el doble e inseparable significado del término historia es característico de una sociedad determinada, precisamente la sociedad occidental, que se auto-comprende y auto-proyecta a sí misma históricamente, mediante el saber de la Historia y el poder del Estado. Por ello mismo, Hegel entiende la Filosofía de la Historia como una reflexión sobre el destino de esa sociedad occidental que ha impuesto su saber y su poder al resto del mundo, es decir, como una crítica histórico-política de su propia época, la llamada época «moderna».

Después de Hegel, otros muchos «filósofos de la historia» han subrayado el doble significado del término historia, pero lo han hecho para oponerse a Hegel, y, de modo más general, para contraponer entre sí —no por medio de una relación dialéctica, sino por medio de una alternativa excluyentedos maneras de entender la Filosofía de la Historia. Así, a los filósofos que pretenden ocuparse de la historia como una realidad objetiva (tal sería el caso de Kant, Hegel, Marx, Comte, etc.), se les acusa de entender la filosofía

\footnotetext{
32 Hegel, G. W. F., Lecciones..., op. cit., p. 137.

33 Hegel, G. W. F., Lecciones..., op. cit., pp. 137-138.

34 Hegel, G. W. F., Lecciones..., op. cit., p. 137.
} 
a la manera tradicional, como la ciencia suprema o ciencia de las ciencias, es decir, se les acusa de pretender suplantar a la ciencia empírica moderna mediante la construcción de una metafísica de la historia, y a esta metafísica la denominan «filosofía especulativa o sustantiva de la historia». Por el contrario, estos autores anti-metafísicos consideran que de la realidad objetiva solo puede ocuparse el científico (en este caso, el historiador), mientras que el filósofo debe limitarse a elaborar una reflexión meta-científica o epistemológica sobre el saber historiográfico, y a esta reflexión epistemológica la denominan «filosofía crítica o analítica de la historia».

Además, estos autores anti-metafísicos consideran que la «filosofía especulativa o sustantiva de la historia» es una reminiscencia del pasado premoderno, una prolongación de las especulaciones cosmológicas y teológicas de la tradición greco-cristiana. Este es el argumento expuesto ya por Dilthey en 1883, en su Introducción a las ciencias del espíritu, y repetido a lo largo del siglo xx por otros muchos y muy diversos filósofos: Collingwood, Popper, Aron, Walsh, Danto, etc. ${ }^{35}$. Ninguno de estos autores parece darse cuenta de que al hacer semejante juicio histórico sobre la superación de la metafísica greco-cristiana por la ciencia moderna, están hablando de la historia de Occidente como una realidad objetiva y están haciendo, por tanto, una "filosofía especulativa o sustantiva de la historia» no muy diferente de la de Hegel o Comte. Y, por otro lado, cuando tratan de fundamentar su reflexión epistemológica sobre el saber historiográfico, no pueden dejar de encontrarse una y otra vez, como le sucedió al propio Dilthey, con la historicidad existencial del historiador que elabora dicho saber y la del propio epistemólogo que examina sus condiciones de validez.

Estas dos objeciones que cabe hacerles a los epistemólogos de la historia -o, más exactamente, a quienes conciben la Filosofía de la Historia de forma unidimensional, como mera epistemología- nos indican, por sí solas, que la distinción dicotómica entre el sentido «objetivo» y el sentido "subjetivo» del término historia es insuficiente. Porque la realidad histórica a la que apunta el sentido "objetivo» del término posee una doble dimensión: por un lado, se trata de la historia empírica y singular de Occidente; por otro lado, se trata de la historicidad trascendental y universal de la experiencia humana en cuanto tal.

El propio Hegel, desde el momento en que habla de sociedades «prehistóricas» y sociedades «históricas», y atribuye exclusivamente a estas últimas la peculiaridad de tener a un tiempo historia "objetiva» e historia "subjetiva», está dando al término historia un tercer sentido (a un tiempo "objetivo»y "subjetivo»), con el que pretende nombrar el destino singular de la sociedad

35 Dilthey, D., Introducción a las ciencias del espíritu. Ensayo de una fundamentación del estudio de la sociedad y de la historia, Madrid, Alianza, 1980; Collingwood, R. G., Idea de la historia, México, FCE, 1952; PopPer, K. R., La miseria del historicismo, Madrid, Alianza, 1973; Aron, R., Introducción a la filosofía de la historia. Ensayo sobre los límites de la objetividad histórica, Buenos Aires, Losada, 2007; Walsh, W. H., Introducción a la filosofía de la historia, México, Siglo XXI, 1968; DAnTo, A. C., Historia y narración. Ensayos de filosofía analítica de la historia, Barcelona, Paidós/ICE de la UAB, 1989. 
occidental en el conjunto de las sociedades humanas. La sociedad occidental, que es precisamente la sociedad en la que surgen simultáneamente la Filosofía y la Historia (y, con ellas, la Historia de la Filosofía y la Filosofía de la Historia), es una sociedad histórica no simplemente por estar sometida al curso objetivo del tiempo, como cualquier otra sociedad, ni simplemente por contar con un saber histórico, con el que también han contado otras sociedades (en particular, las que han tenido una tradición escrita), sino por auto-comprenderse y autoproyectarse a sí misma históricamente, es decir, por considerarse enjuiciadora y hacedora autónoma de su propio destino y del destino de las otras sociedades, en el marco de la Historia Universal de la Humanidad, concebida como una historia única y teleológica.

En cambio, si hablamos de la realidad histórica en general, es decir, de la historicidad trascendental de la experiencia humana en cuanto tal, ya no nos estamos refiriendo al destino singular de Occidente, sino a las condiciones universales de la vida humana, a lo que tienen de común todos los pueblos e individuos humanos por el mero hecho de habitar en el mundo. En los últimos años de su vida, sobre todo a partir de 1900, el propio Dilthey se dio cuenta de la imposibilidad de elaborar una reflexión epistemológica sobre el saber histórico (y, en general, sobre las "ciencias del espíritu») sin elaborar una reflexión ontológica sobre la historicidad de la experiencia humana.

En un principio, pretendía prolongar y completar la Crítica de la razón pura de Kant (considerada por Dilthey como una fundamentación epistemológica de las «ciencias de la naturaleza»), mediante una «crítica de la razón histórica» (que habría de proporcionar ese mismo fundamento epistemológico a las «ciencias del espíritu»). Pero esta pretensión inicial le llevó, finalmente, a cuestionar los presupuestos racionalistas de Kant, a plantearse una «crítica histórica de la razón», a elaborar su teoría de la "concepción del mundo» (Weltanschauung) como expresión de la existencia histórica singular de cada pueblo y de cada época, y a encontrar en la experiencia hermenéutica, interpretativa e intersubjetiva de la "comprensión» (Verstehen) no simplemente el modo de saber propio de las "ciencias del espíritu», sino también el modo de ser propio de los seres humanos, es decir, la condición trascendental de nuestra experiencia del mundo ${ }^{36}$.

El camino que llevó a Dilthey de la «ciencia» historiográfica a la «vivencia» histórica, y, por tanto, de la epistemología a la ontología, fue proseguido y radicalizado por Heidegger en Ser y tiempo ${ }^{37}$. Heidegger no se propone una fundamentación epistemológica de la historiografía y, en general, de las «ciencias del espíritu», sino una nueva «ontología fundamental» que ponga en cuestión la metafísica subyacente al racionalismo moderno. Esta nueva

36 Dilthey, W., Obras VIII. Teoría de la concepción del mundo, México, FCE, 1945. Para este giro ontológico de la hermenéutica, véase: Ferraris, M., Historia de la hermenéutica, Madrid, Akal, 2000.

37 Heidegger, M., Ser y tiempo, o.c., especialmente el cap. V de la segunda sección, titulado «Temporeidad e historicidad» (pp. 389-418), en donde el autor «dialoga» con Dilthey. 
ontología postula como punto de partida inexcusable el replanteamiento de las relaciones entre el ser y el tiempo, la puesta en cuestión de la vieja «metafísica de la presencia», y, como primer paso, el análisis fenomenológico de la historicidad o temporalidad constitutiva del ser humano. Para Heidegger, la «comprensión» (Verstehen) no es ya un método de conocimiento - el método propio de las "ciencias del espíritu», contrapuesto al método de la «explicación»(Erklären), propio de las ciencias naturales-, sino que pasa a ser el modo de ser (o estar) en el mundo propio del ser-ahí (Dasein), es decir, de ese ser que somos, en cada caso, nosotros mismos. La "comprensión» no es ya un correlato o sustituto de la «explicación», sino la condición constitutiva de la vida humana, y la «explicación» pasa a ser una forma derivada y restringida de "comprensión». Existir es ya comprender, y este comprender no se reduce al ámbito intelectual o cognoscitivo, sino que incluye también el ámbito pragmático, la posibilidad de orientarse en el mundo. Y esto es así porque la comprensión no está referida solo al pasado sino también al porvenir, y porque entre ambos «ec-stasis» del tiempo se da una relación de mutua remisión.

Por un lado, esta comprensión u orientación existencial está condicionada por una tradición, por un mundo histórico heredado, por unos determinados «prejuicios» que le son dados o legados al ser humano desde el momento en que nace en el seno de una comunidad determinada. Pero, por otro lado, estas condiciones heredadas son el horizonte de posibilidad en el que el ser humano puede comprenderse a sí mismo, orientarse en el mundo y proyectarse hacia el futuro. Es siempre una determinada situación de «pre-comprensión» la que permite al ser humano tanto la proyección hacia el futuro como la apropiación del pasado. Más aún, es la apertura hacia el futuro la que le permite la comprensión o apropiación del pasado. En efecto, la «situación hermenéutica», en la que el viviente humano se experimenta «arrojado» dentro de una determinada realidad histórica, es también una situación de apertura temporal, que le permite comprender el pasado desde el presente y proyectarlo hacia el porvenir: el pasado es comprendido en función de las posibilidades abiertas por el futuro, y el futuro, a su vez, es proyectado en función de las posibilidades abiertas por el pasado.

Desde esta perspectiva, la actividad historiográfica no es más que una forma particular de apropiación del pasado, pero esta apropiación está a un tiempo limitada y posibilitada por la realidad existencial en la que el historiador se encuentra ya de entrada «arrojado». En otras palabras, antes de conocer historiográficamente el pasado, y para poder conocerlo, ese pasado tiene que haberle sido dado al historiador, ya de entrada, como condición de su propia experiencia, es decir, el historiador ha de encontrarse, ya de entrada, de algún modo afectado e interpelado por ese pasado.

En resumen, Heidegger rechaza (como ya lo había hecho Hegel) que la filosofía haya de verse reducida a mera ancilla scientiae, a mera reflexión epistemológica o meta-científica sobre los saberes empíricos, y en particular sobre el saber historiográfico. No niega la conveniencia de tales reflexiones epistemológicas, pero considera que son de carácter derivado y que deben 
buscar su fundamento último en una reflexión ontológica sobre la historicidad trascendental de la vida humana. Mediante este giro ontológico que Heidegger dio a la epistemología hermenéutica de Dilthey (y que posteriormente ha sido proseguido por autores como Gadamer y Ricoeur ${ }^{38}$, la Filosofía de la Historia es entendida y practicada como una ontología de la historicidad.

\section{VI}

Tenemos, pues, tres posibles mapas. En primer lugar, el mapa que establece una disyunción excluyente entre las «filosofías especulativas, sustantivas o metafísicas», propias del pasado, y las «filosofías críticas, analíticas o epistemológicas», propias del presente; según esta clasificación, la Filosofía debería limitarse a ser una ancilla historiae. En segundo lugar, el mapa que establece una derivación unilateral entre la ontología de la historicidad, que sería el discurso primario y universal, y la epistemología de la historiografía, que sería un discurso secundario y particular; en este caso, es la Historia la que debería convertirse en ancilla philosophiae. En tercer lugar, el mapa que establece una relación dialéctica entre la historia como realidad «objetiva» y la historia como narración "subjetiva», entre el ser y el saber, pero también entre el saber de la "historia empírica» y el saber de la "historia filosófica», y que asigna al Occidente euro-atlántico el privilegio de haber realizado semejante sintesis entre Objeto y Sujeto; en este caso, se pretende resolver el conflicto entre Historia y Filosofía, afirmando su identificación definitiva en un supuesto «Juicio Final de la Historia».

Ninguno de estos tres mapas me parece satisfactorio, porque ninguno de ellos reconoce el carácter irresoluble e indecidible del conflicto entre la Filosofía y la Historia, es decir, entre lo trascendental y lo empírico, entre la universalidad de la ley y la singularidad del caso $^{39}$. Por eso, voy a proponer aquí un cuarto mapa, que no tiene una estructura dual, como los otros tres - sea la dualidad de la disyunción excluyente, o la de la derivación unilateral, o la de la síntesis dialéctica-, sino una estructura triangular, en la que cada uno de los ángulos remite simultáneamente a los otros dos.

Así, frente a quienes pretenden reducir la Filosofía de la Historia a mera epistemología, conviene recordar que es la propia reflexión epistemológica la que nos lleva, inevitablemente, más allá de sí misma: por un lado, nos lleva a una interrogación ontológica sobre la historicidad de la vida humana, es decir, sobre las condiciones trascendentales de la experiencia, que son a un tiempo el límite y el horizonte de posibilidad del propio saber historiográfico; por otro lado, nos lleva a una interrogación sobre el destino singular de la

38 GadAmer, H.-G., Verdad y método. Fundamentos de una hermenéutica filosófica, Salamanca, Sígueme, 1977; Ricoeur, P., op. cit.

39 Sobre la noción de «indecidibilidad», véase Derrida, J., Fuerza de ley. El «fundamento místico de la autoridad», trad. de Barberá, A. y Peñalver, P., Madrid, Tecnos, 1997. 
sociedad occidental, pero también sobre el proceso de modernización y globalización de todas las relaciones sociales, es decir, sobre nosotros mismos, los seres humanos de comienzos del siglo XXI, que nos auto-comprendemos por medio del saber historiográfico y nos auto-afirmamos por medio de la acción ético-política, y que sin embargo ya no creemos en la concepción evolutiva y eurocéntrica de la Historia Universal de la Humanidad. Estos dos tipos de interrogaciones desbordan el campo de la epistemología, pero la epistemología tiene que remitirse a ellas y darlas por presupuestas precisamente para poder delimitar su propio campo de reflexión.

La historiografía no puede dejar de remitir a la historicidad, por lo que la reflexión epistemológica no puede dejar de remitir a la reflexión ontológica. Pero esta reflexión ontológica, a su vez, si se limita al análisis de la historicidad como condición trascendental de la experiencia humana y se desentiende de lo que Nietzsche llamaba la «historia efectiva» (wirkliche Historie) de la vida humana, corre el riesgo de convertirse en una antropología abstracta y ahistórica, en manifiesta contradicción con su pretendida ontologización o radicalización de la historicidad humana. Si queremos ser consecuentes con esta ontología de la historicidad, tenemos que problematizar la oposición misma entre lo trascendental y lo empírico, o lo universal y lo singular, pues no es posible disociar la historicidad trascendental del ser humano de las concretas condiciones histórico-políticas en que empíricamente se da. El propio Heidegger se verá obligado a reconocerlo, aunque sea de manera muy oblicua y oscura, sobre todo tras su compromiso ético-político con el nazismo. De ahí el giro (Kehre) que le llevará de Ser y tiempo a las obras publicadas tras la Segunda Guerra Mundial, en las que la relación entre el ser del mundo y el ser de los humanos se revela como una relación histórica, como un destino abierto e incierto, como un "acontecimiento» (Ereignis) en el que ambos no están constituidos y enfrentados de una vez por todas, sino que mantienen un vínculo de recíproca apropiación-expropiación (Uebereignen). Así es como Heidegger se ve conducido a reflexionar sobre el destino de Occidente como "era de la técnica» y a dialogar con Hegel, reemplazando el concepto hegeliano de progreso o de «superación» (Aufhebung) por el concepto de recurrencia, variación o «paso atrás» (Schritt zurück) ${ }^{40}$.

Ahora bien, si la ontología de la historicidad nos lleva a la crítica del destino de Occidente, simultáneamente debe llevarnos a reconocer el lugar decisivo del saber historiográfico - y, en general, de los saberes científicos, tanto naturales como sociales- en la comprensión de ese destino. Si nuestra concreta experiencia del mundo, en cuanto hijos de la era moderna, nos lleva a reconocernos como seres a un tiempo biológicos e históricos, esto se debe a que dicha experiencia está configurada por los saberes científicos, mientras que la de otras épocas o sociedades ha estado configurada por otras formas

40 Heidegger, M., Identidad y diferencia, texto bilingüe, ed. de Leyte, A., Barcelona, Anthropos, 1988. 
de pensamiento, como el mito o la religión. En otras palabras, no habría sido posible una «ontología fundamental» acerca de la historicidad como esencia constitutiva del ser humano, ni una crítica del destino de Occidente como «historia del (olvido del) Ser», si la historiografía no hubiera configurado de manera tan decisiva nuestra experiencia del mundo. Pero esto es algo que Heidegger no llegó a reconocer.

En pocas palabras, una reflexión ontológica sobre la historicidad sería imposible si no remitiera simultáneamente a una reflexión epistemológica sobre la historiografía y a una reflexión crítica sobre la historia de Occidente. Pero estas dos reflexiones, epistemológica y crítica, no pueden ser consideradas como simples derivaciones de la reflexión ontológica, puesto que la ontología de la historicidad depende de ellas y tiene que darlas por presupuestas para delimitar su propio campo de ejercicio.

Llegamos, por último, al tercer ángulo del triángulo: entre la epistemología de la historiografía y la ontología de la historicidad, la crítica de la historia efectiva del Occidente moderno juega un decisivo papel de mediación. Por un lado, pretende llevar a cabo un juicio sobre las condiciones de posibilidad de la propia experiencia, como lo hace la ontología, pero no se interesa por las condiciones universales o trascendentales, sino más bien por las condiciones epocales o empíricas; se trata, pues, de una «ontología de la actualidad», según la expresión de Foucault. Por otro lado, esa «ontología de la actualidad» no puede ser practicada más que recurriendo a la historiografía, pero no ya para realizar una mera reflexión epistemológica sobre ella, ni tampoco para llevar a cabo una mera investigación empírica acerca del pasado, sino para realizar lo que Foucault llama una «historia del presente», es decir, una investigación a un tiempo historiográfica y filosófica acerca de la propia época, un juicio a un tiempo epistemológico y político sobre nuestras propias condiciones de experiencia.

En resumen, la expresión Filosofía de la Historia no nombra un territorio definido, sino tres regiones diferentes que mantienen entre sí complejas relaciones fronterizas. Es cierto que algunos autores han pretendido atribuir legitimidad exclusivamente a una de esas regiones, la de la epistemología, concibiéndola como un saber auxiliar o una simple provincia del imperio científico de la Historia, y denegando toda legitimidad a cualquier otra región que siga todavía fiel a la desacreditada jurisdicción de la Filosofía. Es cierto que otros autores, en oposición a los primeros, han reclamado la jurisdicción suprema para la reflexión ontológica y han tratado de subordinar a ella la región de la epistemología, manteniendo de este modo a la Historia y al resto de las ciencias bajo la tutela de la Filosofía. Pero queda todavía una tercera región, la de la crítica del presente, tal vez la región fronteriza por excelencia, en la que ambas jurisdicciones son puestas en conflicto o en cuestión, viéndose así forzadas a justificarse la una ante la otra.

Cuando Kant se propuso llevar a cabo una «crítica» de las condiciones de posibilidad de la experiencia humana, tuvo que comenzar por reconocer el carácter fragmentado y plural de esa experiencia, es decir, tuvo que comenzar 
por delimitar diversos dominios de la misma: el teórico, el práctico, el estético y el histórico-político. Tuvo que asignar a cada uno de esos dominios una lógica propia, una legitimidad autónoma; pero, al mismo tiempo, tuvo que determinar los pasos, las interconexiones, las mutuas remisiones entre unos y otros dominios. Una tarea análoga es la que ha de llevar a cabo la Filosofía de la Historia: se trata de diferenciar tres dominios irreductibles entre sí, cada uno con su lógica propia, cada uno con sus propios problemas; pero, al mismo tiempo, se trata de mostrar que esos tres dominios son inseparables entre sí, y que no cesan de remitirse el uno al otro.

Universidad de Murcia

Antonio Campillo

Departamento de Filosofía

campillo@um.es - http://webs.um.es/campillo

[Artículo aprobado para publicación en diciembre de 2015] 